\title{
Sample Preparation Method for Scanning Force Microscopy
}

\author{
I.R. Jankov ${ }^{1}$, R.N. Szente ${ }^{2}$, I.D. Goldman ${ }^{1}$, M.N.P. Carreño ${ }^{3}$, \\ J.W. Swart ${ }^{4}$, and R. Landers ${ }^{5}$ \\ ${ }^{1}$ Instituto de Física, Universidade de São Paulo, São Paulo, SP, Brazil \\ ${ }^{2}$ Mechanical and Electrical Division, IPT, Cidade Universitária, \\ CEP 01064-970, São Paulo, SP, Brazil \\ ${ }^{3}$ Laboratório de Micro Eletrônica, Escola Politécnica, \\ Universidade de São Paulo, São Paulo, SP, Brazil \\ ${ }^{4}$ CCS, Universidade de Campinas, Campinas, SP, Brazil \\ ${ }^{5}$ Instituto de Física, UNICAMP, Campinas, SP, Brazil
}

Received on 21 May, 2001

\begin{abstract}
We present a method of sample preparation for studies of ion implantation on metal surfaces. The method, employing a mechanical mask, is specially adapted for samples analysed by Scanning Force Microscopy. It was successfully tested on polycrystallyne copper substrates implanted with phosphorus ions at an acceleration voltage of $39 \mathrm{keV}$. The changes of the electrical properties of the surface were measured by Kelvin Probe Force Microscopy and the surface composition was analysed by Auger Electron Spectroscopy.
\end{abstract}

\section{Introduction}

Changes induced on a surface due to a certain process can be, in principle, detected by two different types of measurements: a) the determination of the absolute value of the sample characteristics before and after the process that induced the changes; b)the use of a direct comparison, i.e., relative measurements, between the sample (or part of if) that did not undergo any process and the sample (or part of it) that was exposed to the changing process.

The first type of measurement usually requires a standard reference sample with characteristics (the ones of interest) that are well defined and do not change with time. However, a possible problem with this approach is that even the characteristics of the standard reference samples are not always constant and might vary with some unknown experimental parameter (for changes of some properties of gold; see for example [1]). This is particularly the case for measurements not performed under UHV conditions [2,3]. Even measurements under UHV conditions might not provide absolute values unless the standard reference sample is prepared in situ.

The major advantage of the second type of measurements is that there is no need for the separate standard reference sample, since the reference value can be obtained from the sample itself. In this case, it is possible to envision a method where part of the sample is exposed to the modifying process while the other part of the sample is kept at the same initial conditions, thus avoiding the need of a separate standard reference.

In this paper, we use the second approach to propose a sample preparation procedure for scanning force microscopy (SFM) studies. The procedure creates, on the same sample, two types of regions, i.e., one region that is exposed to the modifying process and another region that is not modified. In the case presented here the modifying process was ion implantation, which induced various changes on the material, including work function changes, determined by a Kelvin Probe Force Microscopy [4-6].

The validity of the proposed method is based on two assumptions:

a) during the modifying process the characteristics of parts of the samples not exposed to the process remain constant;

b) after the changes were induced in certain regions of the sample, the characteristics of every region (exposed or not to the modifying process) are assumed to evolve in the same way. 


\section{Experimental procedures}

\section{II.1. General description}

In order to prepare a sample for KPFM using the second methodology presented above, a mechanical mask with fine definition, positioned above the substrate, was used as described below.

The experimental procedures involved the choice of materials to be studied, the method of ion implantation to be used, the design and construction of a suitable tool in order to have, in the same sample, areas exposed and not exposed to the ion implantation process (according to the method proposed above), and surface analysis of the produced sample. Specifically, the developed experimental procedures consisted of the following steps: a) Sample preparation b) Production of a mechanical mask; c) Ion implantation process; d) Surface analysis. A more detailed description of these steps is given below.

\section{II.2. Sample preparation}

The method developed for preparing samples that are partially exposed to a modifying process was carried out on polycrystalline copper.

First, the substrates were mechanically abraded with sand paper up to 2400 mesh. After cleaning in ethanol, the polishing process was continued with diamond pastes (produced by $K G$ Sorensen) of $6 \mu \mathrm{m}, 3$ $\mu \mathrm{m}$ and $1 \mu \mathrm{m}$ in grain size respectively. The substrates were cleaned in ethanol and distilled water after each step. After the polishing process, the samples were examined using an atomic force microscope for determining the substrate topography. In these measurements, the maximum topography difference was of the order of 250nm as it can be seen in Fig.1.

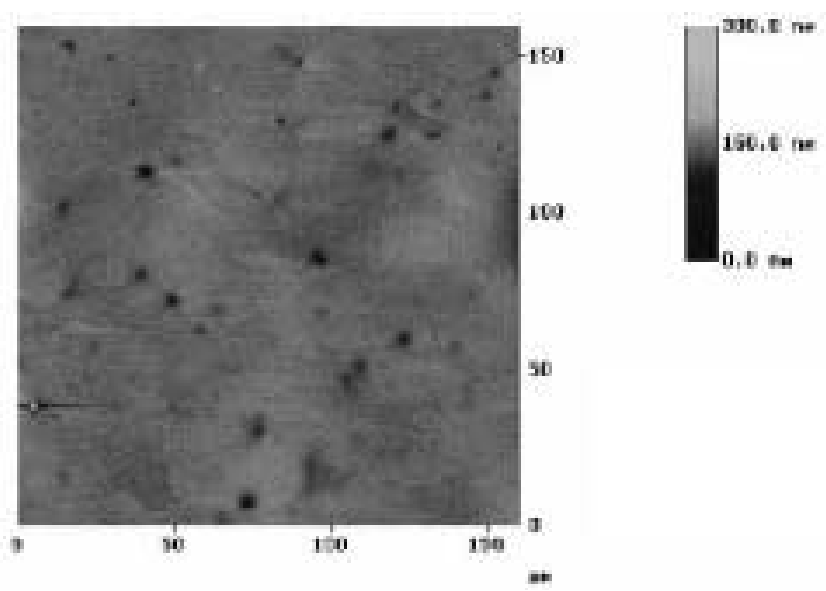

Figure 1. Topography of copper substrate measured with AFM.

\section{II.3. Mechanical mask}

A special mechanical mask was designed and manufactured to be used during the ion implantation process.

The main objective for using a mechanical mask on the top of the sample undergoing an ion implantation process is to create, on the sample surface, a determined pattern of implanted and non-implanted regions. This allows the determination of changes induced by the process on the same sample as explained above (although some surface analyses were carried out for different samples exposed to the same process). The main points which were considered in the design of the mask are presented below, and followed by the description of the production steps used in manufacturing of the mechanical mask.

\section{II.3.1 Design of the mechanical mask}

The design of the mechanical mask had to take into consideration the following limitations and characteristics:

1. The piezoelectric device of a SFM equipment limits the maximum scanned area to around $100 \times 100 \mu \mathrm{m}$ for a typical configuration. If one wants to be sure that, within this scanned area, there is at least one border region (between the regions with and without implanted ions) the mask has to create regions smaller than a few tenths of a micron.

2. Since SFM measurements cannot provide surface composition, the mechanical mask should allow the production of two samples simultaneously under the same conditions. This would provide one sample to be used in the SFM measurements and another one (presumably identical to the first sample) to be used in the composition determination. This procedure is due to the fact that most of the surface analyses are destructive; if one sample is used for both types of analyses, there will be always uncertainty if some sample characteristics were changed during the ion implantation process or during the previous analysis.

3. Depending on the dose of ions implanted on the sample, it could be impossible to differentiate an implanted from a non implanted area. This could hinder the measurements of the changes induced on the 
sample by the process due to the impossibility of determining the border between the implanted and the non- implanted regions. Therefore, the mask should create the largest possible number of borders (this means the largest possible number of separate implanted regions).

4. The dimensions of the mask were also limited by the equipment used in its production and by the equipment used in the process of ion implantation.

A special version of the programme AutoCAD 10 was used for the design of the mechanical mask. The design of the mechanical mask used in this work can be seen in Fig.2.

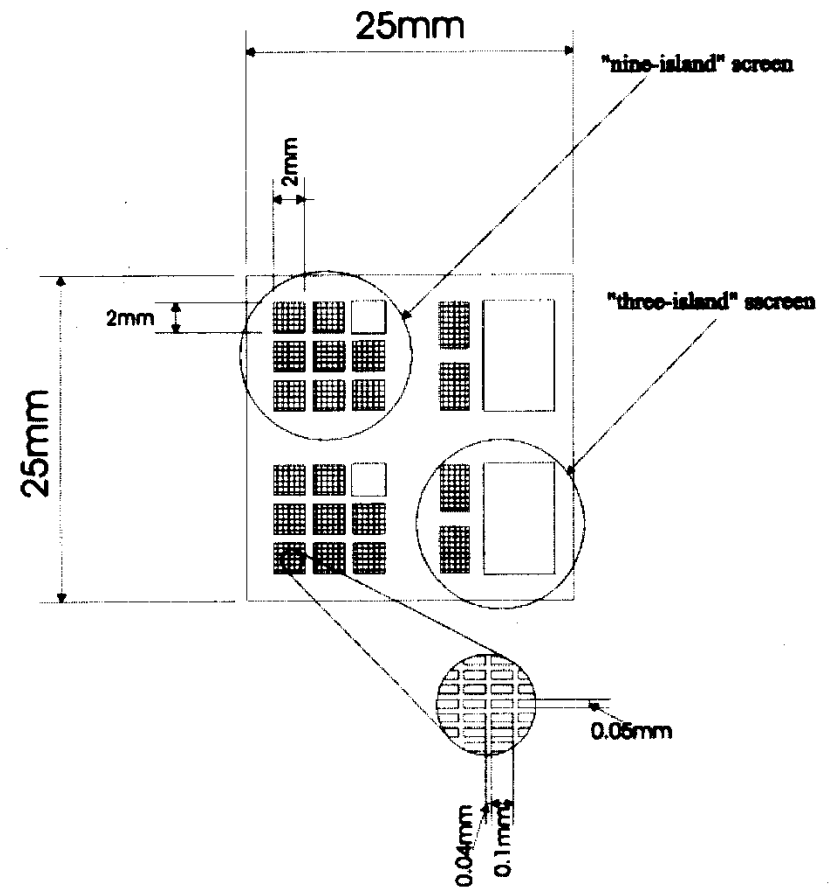

Figure 2. The mechanical mask lay-out (front part).

The used ion implantation equipment limited the mask size to $25 \times 25 \mathrm{~mm}$. The mask can be used for the production of two pairs of samples simultaneously (in case just one pair is needed, half of the mask can be covered during the ion implantation). Two different types of features can be seen on Fig.2.: a "nine-island" screen and a "three-island" screen. The sample for the SFM measurements is placed under the "nine-island" screen and the sample for surface composition analysis under the "three-island" screen. Eight out of the nine regions on the "nine-island" screen and two out of the three regions on the "three-island" screen contain hundreds of rectangular areas with size of $100 \times 40 \mu \mathrm{m}$ (those rectangular areas are actually holes in the screen).
The screen is approximately $4.5 \mu \mathrm{m}$ thick and should be able to stop completely phosphorus ions with up to $24 \mathrm{MeV}$ acceleration voltage (the fact whether an ion beam with certain energy can be stopped depends on the screen thickness). The ion beam will just pass through the rectangular areas, thus changing the properties of the sample in the rectangular-shaped regions. The reason for having eight separate regions with rectangular structure on the "nine-island" screen instead of one big region, is that the screen material is fragile and can crack due to the surface tension. The spacing between the rectangular areas is $50 \mu \mathrm{m}$, which is sufficient for distinguishing between the implanted and non-implanted regions (implanted ones should be narrower).

The regions without the rectangular structure on the "nine-island" screen and the "three-island" screen are actually large holes in the screen (with sizes of $2 \times 2$ $\mathrm{mm}$ and $8.5 \times 5.5 \mathrm{~mm}$ respectively) where an ion beam can pass and hit the sample surface uniformly. On the "nine-island" screen, the region without the rectangular structure was designed to facilitate the search for the areas of interest on the sample after the ion implantation process (in case the implanted areas are not visible, the sample surface can be marked through this hole). The region without the rectangular structure on the "three- island" screen was designed in order to be used for surface composition analysis (the area is sufficiently large for most of the surface composition analysis techniques). The two regions with the rectangular structure on the "three-island" screen can be used for comparison between the SFM results on the sample used just for this type of measurements (i.e. the one under the "nine-island" screen) and the sample used for surface composition analysis (i.e. under the "three-island" screen). In this way, the influence due to the surface composition analysis on the results of SFM measurements can also be studied.

\section{II.3.2. Production of the mechanical mask}

The mask, was designed and manufactured in the MicroElectronic Laboratory of the Polytechnic Engineering School of the University of São Paulo. The production of the mask can be divided into two major stages:

1. Production of chrome pattern masks

Since it is not possible to transfer the desired computer design directly into the silicon mechanical mask used in the ion implantation process, an intermediate mask had to be produced. Those intermediate masks, made of chrome, have the pattern 
originally designed in the computer. Once produced, the intermediate masks can be used for the production of an indefinite number of silicon mechanical masks.

2. Production of silicon mechanical masks

The mechanical mask consists of a substrate, made of silicon, and of a screen, made of silicon, oxygen and nitrogen, created on the silicon substrate. The geometrical pattern from a chrome mask is transferred to the screen material of the mechanical mask. The silicon substrate acts only as a support for the complex oxide screen. The screen is formed on one of the sides of the silicon substrate and the complex oxide on the other side of the substrate is removed almost completely to prevent undesired stopping of ions (the substrate is not removed completely in order to protect the silicon substrate during the silicon corrosion stage; see stage 8 of the mechanical mask production in the Appendix). Therefore, two different chrome pattern masks (one for each side of the silicon substrate) are needed (see Fig.3.).

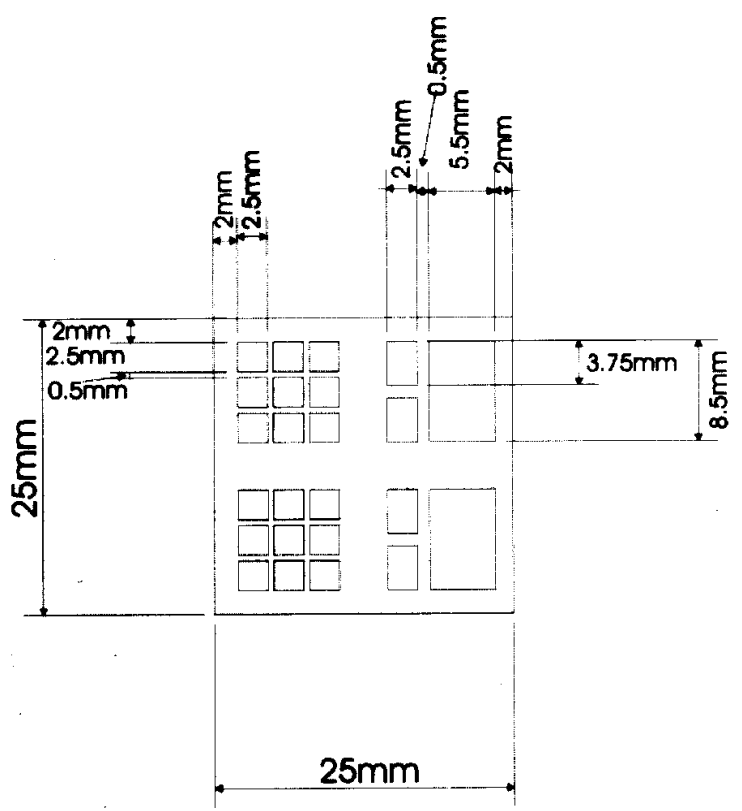

Figure 3. The mechanical mask lay-out (back part).

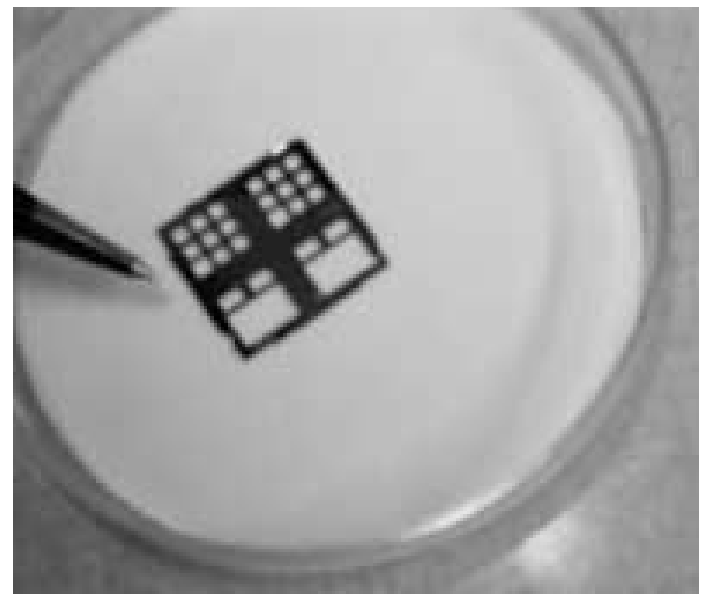

Figure 4. Mechanical mask.

Each of the two major production stages consists of several sub-stages. The steps needed for the production of the chrome pattern and the silicon mask are given in detail in the Appendix. The mechanical mask used in the experiments can be seen in Fig. 4. The small divisions inside each square cannot be identified in this magnification.

\section{II.4. Ion Implantation}

Two polished copper substrates were implanted with phosphorus ions (with a dose of $8.45 \times 10^{15}$ ions $/ \mathrm{cm}^{2}$ ) at an acceleration voltage of $39 \mathrm{keV}$. The ion implantation was performed with an Eaton GA 4204 implanter of the Centre of Semiconductor Components of the University of Campinas. In order to determine the ranges of the phosphorus ions with the acceleration of $39 \mathrm{keV}$, TRIM simulations were performed (SRIM version 2000.10 [7]). In those simulations, 10.000 ions were used and the maximum ion range was around $600 \AA$ (see Fig.5.), thus confirming that the mechanical mask produced here (with a $4.5 \mu \mathrm{m}$ thick oxide layer completely stopping the incident ions) could be used for the experiments.

\section{II.5. Surface Analysis}

One of the two implanted samples was used for Auger Electron Spectroscopy (AES) in order to determine the surface composition. For determining the influence of the ion implantation process on the surface composition of samples, one substrate which did not undergo the ion implantation process was also used for AES. The AES analyses were performed in the Surface Physics Laboratory of the Institute of Physics, University of Campinas.

The other implanted sample was used for Kelvin Probe Force Microscopy (KPFM) measurements in order to measure the Volta Potential distribution, which 
is directly related to the work function of the surface. The Volta Potential between the tip (made of Pt and Ir) and a freshly cleaned polycrystalline copper substrate was used as a reference value. It should be mentioned that the conclusions drawn from these measure- ments are not dependent on which reference material was used. Simultaneously to the Volta Potantial, topography measurements of the copper sample were performed with KPFM equipment. The KPFM analyses were performed in the Laboratory of Material Science and Engineering of the Ohio State University.
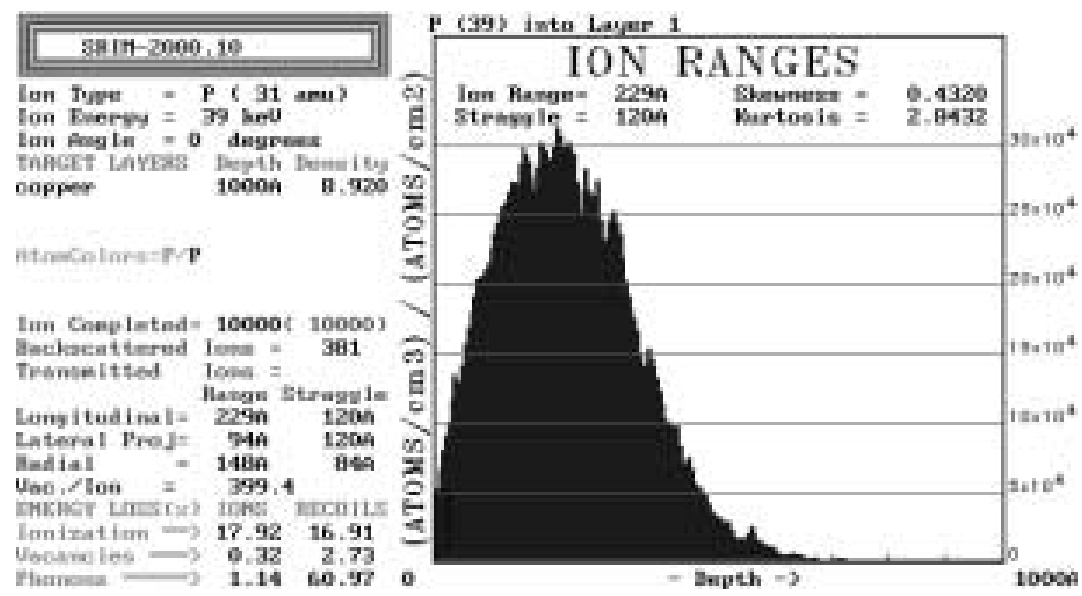

Figure 5. SRIM results for phosphorus ions with energy of $39 \mathrm{keV}$.

\section{Results and Discussion}

One of the most important parts of the preparation procedure for the SFM sample is the treatment received by the substrate. Since changes on the topography of the sample can influence the SFM measurements, great care should be taken in order to produce uniformly planar substrate surfaces. Although the preparation of the copper substrates that were used for the experiments described here yielded good results, the procedure can be further improved. Recently, Wadsak et al. [8] carried out a comparison of different preparation methods of copper substrates for scanning force microscopy investigations.

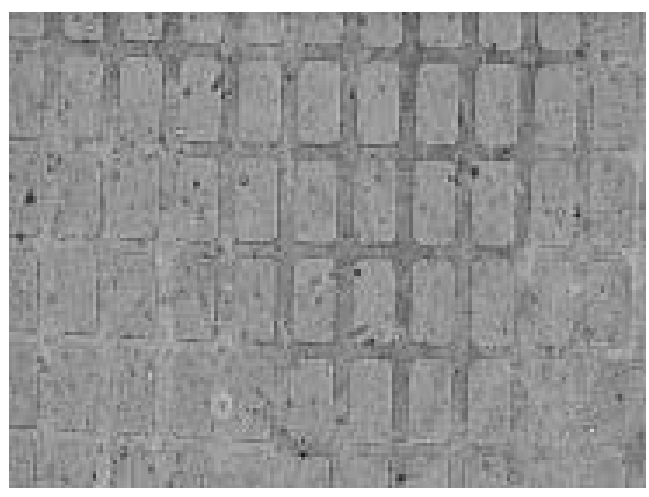

Figure 6. Surface of the implanted copper sample.
The surface of the implanted copper substrates were investigated with an optical microscope. The rectangular areas in Fig. 6. are regions which received phosphorus ions during the ion implantation. The rectangularshaped structure matches the geometrical pattern of the mechanical mask. Some scars on the copper surface were observed, which are probably due to the handling of both the mechanical mask and the copper substrates during the ion implantation process.

The results of AES analyses for the copper substrates (before ion implantation) are shown in Fig.7a. The presence of some contaminants was observed. In order to determine the thickness of the contaminant layer, a thick layer of about $50 \AA$ of the substrate surface was removed by Ar sputtering. The composition analysis of the copper substrate after the sputtering process is shown in Fig.7b.

It can be seen from these figures that only $\mathrm{O}$ and $\mathrm{C}$ are present on the copper surface after the sputtering process. It can be concluded that the other contaminants observed on the copper surface without sputtering $(\mathrm{S}, \mathrm{Cl}$ and $\mathrm{N}$ ) were just part of a contaminant layer of less thickness than $50 \AA$. The fact that $\mathrm{O}$ and $\mathrm{C}$ are still found even after the removal of approximately $50 \AA$ of the surface is expected since copper, in air, forms a relatively thick oxide layer very quickly $[9,10]$. Carbon is probably due to the carbon dioxide present in the atmosphere. 
The results obtained from the AES analysis for the implanted copper sample are shown in Fig. 8. The contaminants found on the copper substrate without ion implantation (Fig. 7.) can also be seen on the implanted sample. One new peak, around $120 \mathrm{eV}$, was found. This peak indicates the presence of phosphorus on the sample surface. It should be noted that no contaminants due to the use of the mechanical mask were found.

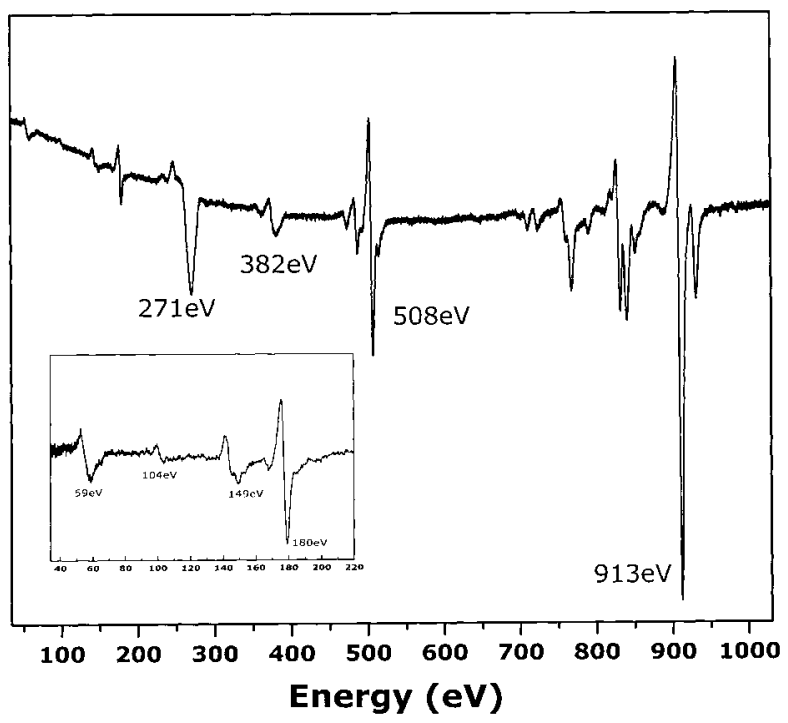

Figure 7a. Copper substrate before sputtering.

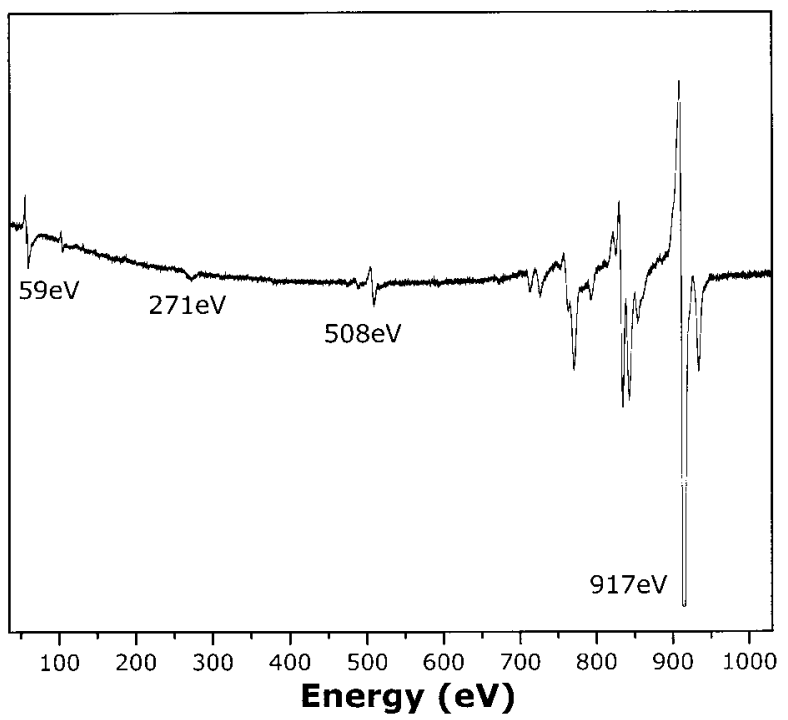

Figure 7b. Copper substrate after sputtering Figure 7. Results of AES for copper substrate.

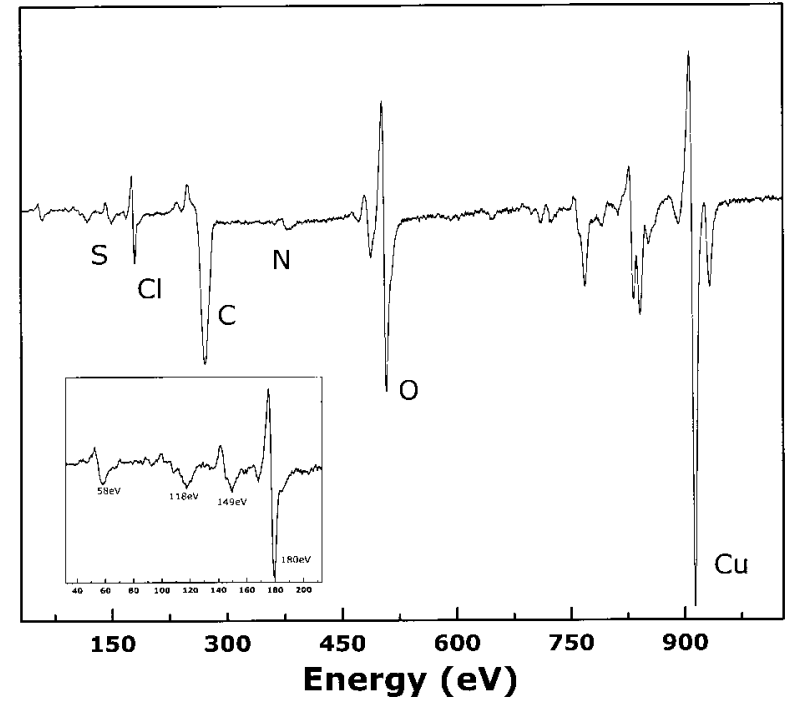

Figure 8. Results of AES for implanted copper sample.

Some topography results and Volta Potential measurements for a certain region of the implanted sample are shown in Fig. 9 (where we can seen the rectangularshaped pattern of the implanted areas.) There are no noticeable changes on the topography of the implanted regions.

Eight different areas with a rectangular-shaped pattern on the same sample were examined for topography and Volta Potential. The results for the Volta Potential are shown in Table 1 . The results for both the implanted and non implanted regions are given with respect to the reference copper substrate used for the measurements. Since the same copper reference is used for the measurements of the implanted and non implanted areas, there is no influence on the obtained results.

The Volta Potential difference indicates the change of the copper work function due to the phosphorus ion bombardment. In this case, an increase of $25 \mathrm{mV}$ in average was observed if we compare the ion implanted region with the non implanted region. Although the values for the Volta Potential difference change slightly from area to area, the work function of the copper clearly shows an increase for the implanted areas as compared with the original copper surface.

It is not yet clear whether the work function changes were induced by the presence of phosphorus on the surface or by the ion implantation process (for example, heating of the sample, change of the topography by sputtering, etc.) [11,12]. Further experiments are needed in order to determine what is the mechanism for the work function increase. Nevertheless, the results of the experiments obtained in this work indicate that the method for creating implanted and non implanted regions in a sample is satisfactory for KPFM and similar measurements. 


\begin{tabular}{|c|c|c|c|}
\hline Area & $\begin{array}{c}\text { Non-implanted } \\
\text { Regions }\end{array}$ & Implanted Regions & $\begin{array}{c}\text { Volta Potential } \\
\text { Difference }\end{array}$ \\
\hline 1 & $0.110 \mathrm{~V}$ & $0.122 \mathrm{~V}$ & $12 \mathrm{mV}$ \\
\hline 2 & $0.150 \mathrm{~V}$ & $0.172 \mathrm{~V}$ & $22 \mathrm{mV}$ \\
\hline 3 & $0.150 \mathrm{~V}$ & $0.170 \mathrm{~V}$ & $20 \mathrm{mV}$ \\
\hline 4 & $0.110 \mathrm{~V}$ & $0.166 \mathrm{~V}$ & $56 \mathrm{mV}$ \\
\hline 5 & $0.150 \mathrm{~V}$ & $0.170 \mathrm{~V}$ & $20 \mathrm{mV}$ \\
\hline 6 & $0.120 \mathrm{~V}$ & $0.150 \mathrm{~V}$ & $30 \mathrm{mV}$ \\
\hline 7 & $0.115 \mathrm{~V}$ & $0.140 \mathrm{~V}$ & $25 \mathrm{mV}$ \\
\hline 8 & $0.155 \mathrm{~V}$ & $0.170 \mathrm{~V}$ & $15 \mathrm{mV}$ \\
\hline
\end{tabular}

Table 1. KPFM results for different areas of an implanted copper sample.

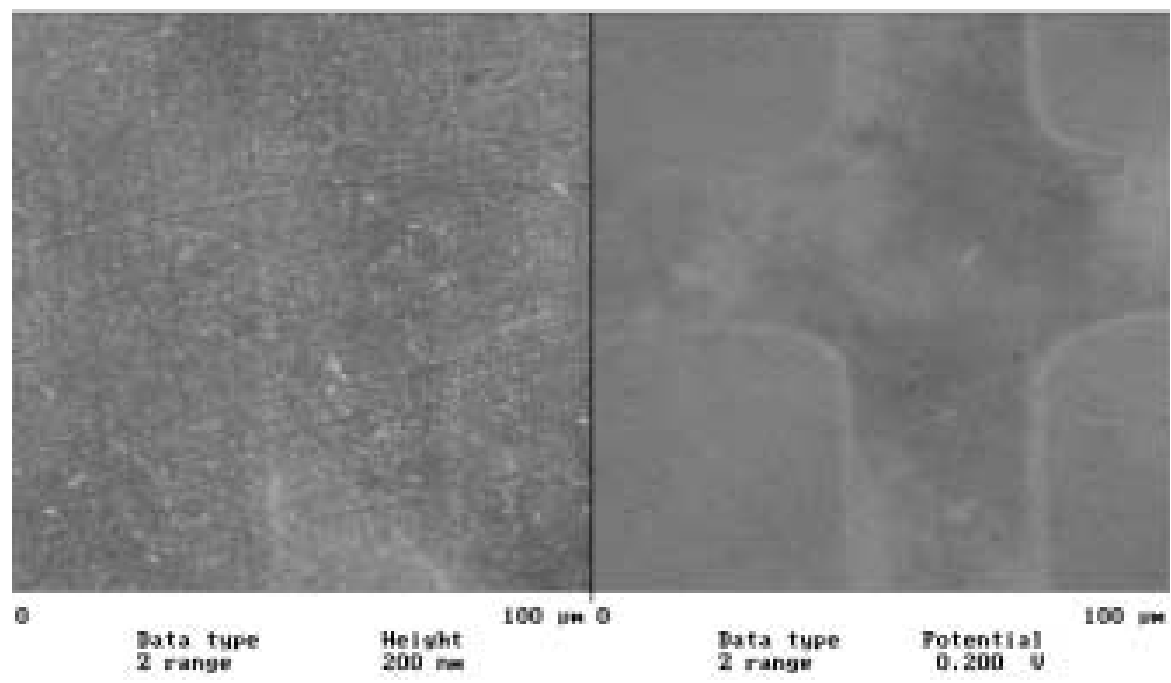

Figure 9. Results of KPFM for implanted copper sample.

It should be noted that the method commonly used in the electronic industry for producing different patterns on a surface, i.e., the method employing a photoresistor directly on the substrate (which would act as the mechanical mask described above), could be used only for one experiment, since the photoresistor would be attached to the sample being prepared. This is one of the advantages of the use of the mechanical mask to prepare samples for KPFM.

\section{Conclusions}

In this paper, we describe a methodology for preparing samples to be used by a KPFM equipment. The method was used to study the influence of ion implantation of phosphorus on the work function of copper.

Changes of the work function on copper surface were noticed due to the implantation of phosphorus ions. However, the determination of the exact mechanism for these changes is left for further work.

\section{Acknowledgements}

One of the authors (I.R.J.) would like to acknowledge the financial support received from FAPESP.

\section{References}

[1] W.N. Hansen, K.B. Johnson, Surf. Sci. 316, 373 (1994).

[2] M. Saint Jean, S. Hudlet, C. Guthmannm, J. Berger, Phys. Rev. B 56, 15391 (1997).

[3] M. Nonnenmacher, M.P. O'Boyle, H.K. Wickramasinghe, Ultramicroscopy 42-44, 268 (1992).

[4] Y. Martin, C.C. Williams, H.K. Wickramasinghe, J. Appl. Phys. 61, 4723 (1987).

[5] J.M.R. Weaver, D.W. Abraham, J. Vac. Sci. Technol. B 9, 1559 (1991).

[6] M. Nonnenmacher, M.P. O'Boyle, H.K. Wickramasinghe, Appl. Phys. Lett. 58, 2921 (1991).

[7] J.F. Ziegler, J.P. Biersack, U. Littmark, The Stopping and Range of Ions in Solids, Pergamon Press, New York (1985). 
[8] M. Wadsak, M. Schreiner, T. Aastrup, C. Leygraf, Appl. Surf. Sci. 157, 39 (2000).

[9] J.C. Yang, B. Kolasa, J.M. Gibson, M. Yeadon, Appl. Phys. Lett. 73, 2841 (1998).

[10] K.I. Tanaka, T. Fujita, Y. Okawa, Surf Sci. 401, L407 (1998).

[11] P.J. Ratcliffe, R.A. Collins, Phys. Stat. Sol. A 78, 547 (1983).

[12] B.J. Love, P.F. Packman, J. Mater. Sci. 33, 1359 (1998).

\section{Appendix}

1) Preparation of the chrome mask. A thin chrome layer $(300 \mathrm{~nm})$ was deposited by a sputtering deposition technique, using a Magnetron Balzers BAS450 Sputtering System, on glass plates (Croning glass) which were rinsed in three different solutions prior to the deposition process:

$80^{\circ} \mathrm{C}$;

15-20 minutes in TriChloroEthylene (TCE) on

$15-20$ minutes in acetone on $80^{\circ} \mathrm{C}$;

15-20 minutes in isopropanol on $80^{\circ} \mathrm{C}$.

2) Cleaning of the chrome masks was performed by placing the prepared chrome wafers in a solution of $\mathrm{H}_{2} \mathrm{SO}_{4}$ and $\mathrm{H}_{2} \mathrm{O}_{2}$ (proportion 3:1) at a temperature of $105^{\circ} \mathrm{C}$ during 15 minutes; and then by cleaning the masks with deionized water for 10 minutes. Afterwards, the chrome masks were immersed in alcohol $\left(40^{\circ} \mathrm{C}\right)$ for 20 minutes and dried with a jet of $\mathrm{N}_{2}$.

3) The photoresistor used in the reported experiments was a positive photoresistor AZ1518 diluted in AZ1500 Thinner (proportion 16:9) produced by Hoechst. The application technique involves two stages: static application of a photoresistor solution on the surface of chrome wafer and subsequent acceleration in the spinner for 30 seconds with constant rotation speed of 4000rpm. This process generates a uniform film of the photoresistor with about $0.7 \mu \mathrm{m}$ of thickness. The chrome masks with a photoresistor were submitted to softbaking for 20 minutes at a temperature of $80^{\circ} \mathrm{C}$.

4) The photoresistor film was then exposed to light using a Micropattern printer, Imagen 100, Research Devices Instruments, at the UV-close spectrum (350$500 \mathrm{~nm})$. The computer coupled to this equipment transfers the designed geometry pattern to the system memory. This image is reproduced on the photoresistor film by exposing the film through the movable slits (which let light pass on the desired regions only). The whole procedure takes approximately 3 hours for each chrome wafer.

5) The parts of the photoresistor film which were exposed to light were removed using a 351 Developer, made by Hoechst, diluted in water (proportion 5:1). The chrome masks were later submitted to a high temperature treatment $\left(90-100^{\circ} \mathrm{C}\right)$ during 30 minutes (hardbaking).

6) The chrome masks with the remaining photoresistor film were placed during 3 minutes in a solution of $160 \mathrm{~g}$ of cerium ammonium nitrate and $45 \mathrm{ml}$ of glacial acetic acid. This solution dissolves unprotected chrome only, leaving intact the photoresistor film and the protected chrome below the film.

In order to remove the remaining photoresistor film, the chrome masks were first immersed for 5-20 minutes in acetone $\left(40^{\circ} \mathrm{C}\right)$ and then in TCE (5-10 minutes). The masks are then washed with a jet of acetone, water and isopropanol.

The production of the silicon mechanical mask is divided into sub-stages (the schematic diagram of the production can be seen in Fig.10.):

1 ) Before the use, the silicon substrates were cut $(25 \times 25 \mathrm{~mm})$ and cleaned, following the steps mentioned below: 15 minutes in a solution of $\mathrm{H}_{2} \mathrm{SO}_{4}$ and $\mathrm{H}_{2} \mathrm{O}_{2}$ (proportion 3:1) at a temperature of $105^{\circ} \mathrm{C} ; 10 \mathrm{~min}-$ utes in tap water; 5 minutes in deionized water filtered with Millipore Milli-Q Plus (water with resistivity of $18.2 \mathrm{M} \Omega \mathrm{cm}) ; 15$ minutes in a solution of $\mathrm{H}_{2} \mathrm{O}, \mathrm{NH}_{4} \mathrm{OH}$ and $\mathrm{H}_{2} \mathrm{O}_{2}$ (proportion $5: 1: 1$ ) at temperatures up to $75^{\circ} \mathrm{C}$; 10 minutes in tap water; 5 minutes in deionized water filtered with Millipore Milli-Q Plus; 15 seconds in a solution of $\mathrm{NH}_{4} \mathrm{~F}(40 \%)$ and $\mathrm{HF}(49 \%)$ (proportion 25:4) BOE Etchant; 15 minutes in tap water; 15 minutes in a solution of $\mathrm{H}_{2} \mathrm{O}, \mathrm{H}_{2} \mathrm{O}_{2}$ and $\mathrm{HCl}$ (proportion 6:1:1) at a temperature of $80^{\circ} \mathrm{C} ; 10$ minutes in deionized water filtered with Millipore Milli-Q Plus;

The substrate was finally dried with a nitrogen jet.

As mentioned, the creation of the oxide layer on the silicon substrate is very important in the process of fabrication of the mechanical mask, since the pattern of the chrome mask is transferred to this layer and not to the silicon substrate.

The oxide layer is created in two steps. First, it occurs a thermo-oxidation and then a deposition of a complex oxide layer ( $\mathrm{Si}, \mathrm{O}$ and $\mathrm{N}$ ). The thermo-oxidation was obtained by placing the substrates in an oven chamber at $1100^{\circ} \mathrm{C}$, filled successively with various gases (first 5 minutes with $\mathrm{O}_{2}$, followed by 25 minutes with $\mathrm{H}_{2} \mathrm{O}$ vapour and finally 40 minutes with $\mathrm{N}_{2}$ ). This process creates a layer of a thermo-oxide of approximately $0.5 \mu \mathrm{m}$.

The deposition of the complex oxide was performed using a PECVD2 system (Plasma Enhanced Chemical Vapour Deposition) using an electric discharge through a mixture of high purity $\mathrm{SiH}_{4}(99.89 \%)$ and high purity $\mathrm{N}_{2} \mathrm{O}(99.999 \%)$. The flow rates of the gases were $37.5 \mathrm{sccm}$ for $\mathrm{N}_{2} \mathrm{O}$ and $15 \mathrm{sccm}$ for $\mathrm{SiH}_{4}$. That process creates a complex oxide film of $\mathrm{SiO}_{x} \mathrm{~N}_{y}$ (the composition analysis of this film determined values of 1.57 for $\mathrm{x}$ and 0.34 for $\mathrm{y})$. Contrary to thermo-oxidation, where the whole substrate surface is uniformly covered with the oxide layer, in the complex oxide deposition stage 
each side of the substrate has to undergo the deposition separately. The appearance of an approximately $4 \mu \mathrm{m}$ thick film takes about 3 hours.

Afterwards, the substrates were rinsed in different solutions: $15-20$ minutes in TCE at $80^{\circ} \mathrm{C} ; 15-20$ minutes in Acetone at $80^{\circ} \mathrm{C} ; 15-20$ minutes in Isopropanol at $80^{\circ} \mathrm{C}$.

The thermo-oxide has a two-fold role. It promotes the adhesion of the deposited oxide film and it gives extra protection to the silicon substrate during the silicon corrosion process (stage 8 of the mechanical mask production). The thickness of the film should be tailored according to the ion species and the energy of the beam used in the ion implantation experiments.

In order to promote the dehydration of the surface a primer was covered on the substrate surface before the application of the photoresistor (the same solution as in the chrome mask production). The thickness of the created photoresistor film was about $2.2 \mu \mathrm{m}$. The silicon substrates with a photoresistor layer were submitted to a softbaking for 20 minutes at a temperature of $80^{\circ} \mathrm{C}$.

A Karl Suss MJB3 Mask Aligner was used for the light exposing process (light of 350-500nm wavelength). This step lasted 100 seconds for each side of the silicon substrate. That equipment uses the chrome pattern masks in order to create the desired pattern on the photoresistor film of the silicon substrate, i.e., light can pass through only if there is no chrome on the pattern mask.

After the light exposing process, the substrates were submitted to the process of developing and hardbaking, described in stage 5 of the chrome mask production.

Before the partial removal of the oxide (just in the areas where the photoresistor film was destroyed) on one side of the substrate, the other side of the substrate was protected with Apiezon ${ }^{\circledR}$. The substrates were placed in a solution of NH4F (40\%) and HF (49\%) (proportion 25:4), BOE ${ }^{\circledR}$ Etchant, for 7 minutes, which removes completely the oxide at the desired areas.

After the partial removal of the oxide layer, the Apiezon ${ }^{\circledR}$ was removed with TCE. The stripping of the photoresistor and the cleaning of the substrate were performed as described in stage 7 of the chrome mask production.

The stages 3-7 were repeated for the other side of the silicon substrate.

After the oxide layer was partially removed on both sides of the substrate, a corrosion process of the silicon substrate was then performed. Only the silicon located below the oxide areas removed in the process (described in stage 6 above) is dissolved. The substrate was placed for 7 hours, at a temperature of $80^{\circ} \mathrm{C}$, in a solution of: $108 \mathrm{ml}$ deionized water; $51 \mathrm{ml}$ isopropanol; $50 \mathrm{~g} \mathrm{KOH}$.

After the corrosion step, the substrates were left 10 minutes in a stream of deionized water and cleaned with isopropilic alcohol. 

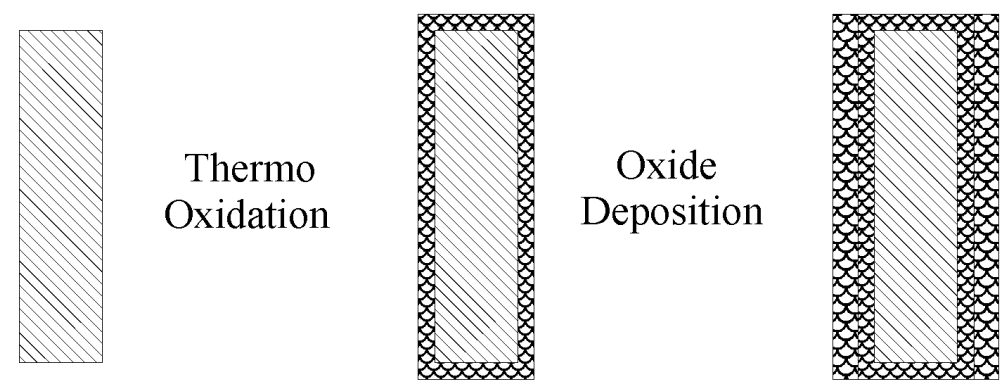

Front Part

Thermo

Oxidation

Oxide

Deposition

Chrome Mask

Photoresisto

Deposition
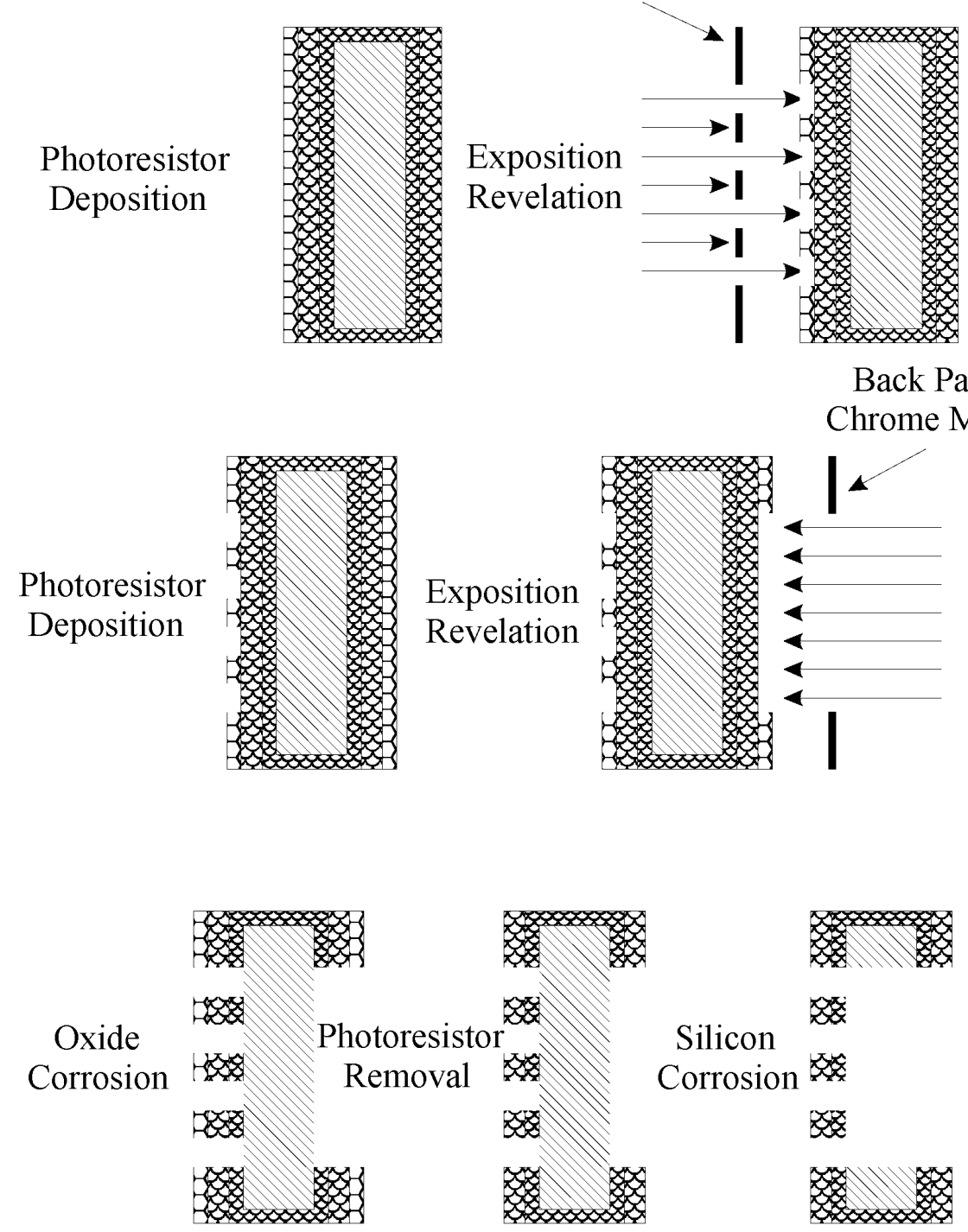

Figure 10. Schematic diagram of the mechanical mask production. 